\title{
Opportunities and challenges of E-learning in Zambia: Experiences and Reflections
}

\author{
*J. Schurgers", G van Stam², S. Banda ${ }^{3}$, M. Labib ${ }^{4}$ \\ ${ }^{1}$ University of Zambia (UNZA), Department of Medical Education, Lusaka, Zambia \\ LinkNet, Macha, Zambia \\ ${ }^{3}$ University of Zambia (UNZA), Department of Medical Education, Lusaka, Zambia \\ ${ }^{4}$ Ass. Prof. Department of Surgery, University of Zambia (UNZA), Lusaka, Zambia
}

\section{INTRODUCTION}

Traditional teaching modalities, such as lecturing are teacher centred and often limiting students input. However still valid teaching and learning strategies, new developments in Medical Education target more student centred strategies, including pro activity of students in order to strengthen delivery of teaching and optimize learning experiences. With the introduction of ICT in education, a new world of possibilities is available to further assist both lecturer and student to maximize the learning experiences. Electronic Learning (better known as e-learning), refers to the educational use of Information and Communication Technologies (ICT). E-learning is providing great opportunities for innovative ways of supporting educational goals, creating interest among students and promoting student-centred self directed learning ${ }^{1,2,3,4}$. Morris ${ }^{5}$ highlights different ways in which e-learning can be integrated into the resources of clinical teachers and mentions various online resources for clinical teachers. Examples of e-learning applications are Youtube ${ }^{6}$, where series of video clips explain e-technologies and the Joint Information System Committee (JISC) which guides on using e-learning technologies in education.

University of Zambia (UNZA) offers an electronic library through the UNZA website ${ }^{8,}$ which is

\footnotetext{
* Corresponding Author:

Juul Schurgers

University of Zambia (UNZA),

Department of Medical Education,

Lusaka, Zambia
}

accessible for lecturers and students alike. Also, collaborative initiatives with Medical schools in the developed world, where ICT and e-learning are advanced, provide opportunities for students in resource limited countries, like Zambia, to benefit from e-learning innovations, ${ }^{9,}$, ${ }^{11}$. However, inadequate hardware capacity, software availability and insufficient internet bandwidth may prevent our students from benefiting from effective e-learning resources and opportunities. This paper explores opportunities of using internet as a learning resource at UNZA and describes experiences with three elearning ICT initiatives between UNZA-School of Medicine and international collaborators from developed countries and discusses challenges and opportunities of e-learning in Zambia.

\section{- University of Zambia electronic library}

Currently, UNZA has an electronic library, accessible through the UNZA website ${ }^{8}$ This eresources library provides over 250 medical journals online, both regional and international, as well as websites with medical information. HINARI, the WHO website with many publications is freely available (as in Africa as a whole), whereas it is not freely accessible in western countries. These journals and website are accessible online for both lecturers and students. Many of these journals provide full articles of publications, which is a good source for further studying and deepening educational experiences for students as well as support thorough literature research for research studies. It also helps lecturers updating their professional knowledge and keeping abreast of new 
developments. It therefore can also be an excellent instrument for continuous professional development.

Opportunities: The e-resources library through UNZA website is rich in useful publications from prominent medical journals, who were previously not accessible for students and lecturers. Hence, through use of ICT and Internet connectivity there are increasing opportunities to find the latest information on relevant topics, learn from regional and international resources in a quick, efficient and cost effective way.

Challenges: Internet connectivity at UNZA is still in its infancy. Internet connectivity at main campus is available, but SOM is still behind with ICT matters and Internet accessibility. At the Medical Library, only ten computers are available for students, connected to the Internet. Most SOM lecturers offices are connected to the Internet via main campus, with variable accessibility and speed of the connectivity due to technical complications. For many SOM students at Ridgeway, accessing the e-resources Library through UNZA website is still a dream; Internet connectivity for students at Ridgeway is not available.

\section{- University of Dundee MedEdWorld synchronous on-line Presentation}

In January and April 2009, the University of Dundee piloted MedEdWorld synchronous online Presentations. Over a dozen universities participated. UNZA, SOM was the only African country among a dozen others from America, Europe and Asia. MedEdWorld ${ }^{12}$ provides an interactive platform featuring audio and video content sharing applications. Sixteen medical students and a facilitator participated from Zambia in the pilots. This electronic platform provided a conferencing facility where participants from different countries discussed specific topics. Students logged into the virtual classroom participating in one hour interactive presentation and responding to questions, through audio and video, text and polled responses. The discussion of the subject matter aimed to promote the application of relevant basic sciences, encourage clinical reasoning and problem solving; and to elicit different perspectives on aspects of the topic.

Students experiences:

"this was the first time I did an e-learning trial and I thought it was going to be a very complicated procedure. However, the process was so user friendly and the instructions were clear and self explanatory. I learned a lot on the use of a TIA/ minor stroke management protocol and how things are being tackled in other countries. I learned a lot from participating fellow students. It is my fervent desire that E-learning be made a continuous way of interactive learning at SOM" (A. M, 6th year medical student)

"It was amazing how we could have discussions with people from all over the world at the same time. Although we could not see all the images shown, it was great to learn from it. Interacting with other students made me realize how much I don't know, I guess this will make me a better student. I want more and more of it"'(W.K., 6th year medical student)

Opportunities: The UNZA-SOM students had the opportunity to participate in a live transnational educational activity. Students could access educational materials prepared in far-away institutions, practice their clinical reasoning and problem-solving and judge their personal standard in comparison to students from other universities. This opportunity sparked an internal driven motivation to learn more about the specific topic. According to the participants they learned more in that specific hour than from many hours of lecturing. 
This type of learning fits in with the desire of the current generation of students for interaction, pro-activity and explorative, exciting learning experiences. The attention of the students was captured due to the exchange of information, the challenge of measuring their knowledge and the active participation. It showed the potential of e-learning as an additional teaching and learning modality which requires less human resources, yet providing challenging and capturing learning experiences for students, with added benefits.

Challenges: The UNZA-SOM did not have computing equipment including laptops/desktops, webcams and headsets and bandwidth to support the participation of the students in the MedEdWorld Classroom. A private Internet provider had to be engaged. During the MedEdWorld Session, reception of images was poor (literally unavailable for some time) and the students had problems with using the ICT equipment effectively. Lack of adequate computing equipments, internet access and students' familiarity with computing equipment were obstacles to fully benefiting from the MedEdWorld experience.

\section{- The Royal College of Surgeon in Ireland's (RCSI) Education Programme for Surgeons (Live Web Conferencing)}

Since May 2008, surgical postgraduate students and surgeons at University Teaching Hospital (UTH), Zambia have participated in five web conferencing e-learning conferences between Lusaka and Dublin. The e-learning conferencing have facilitated on-line discussions of clinical cases, some of which were developed locally through the College of Surgeons of East, Central \& Southern Africa (COSECSA) ${ }^{13}$ faculty in the region. The Web-Conferencing technique allowed faculty and students from different institutions to interact with faculty and postgraduate students elsewhere.

Opportunities: The Zambian students, through elearning facility, have access to learning materials and faculty from the Royal College of Surgeons in Ireland (RCSI). The ratio of trainee to trainer online activity was about 1:8 - one unit of trainer time delivers the same amount of "teaching" to 8 trainees. This means that the e-learning activity is scalable and that it can be used to provide personalized learning to relatively large numbers of trainees. This could have tremendous implications for Africa where faculty numbers are small, when expertise is built up it can be shared very efficiently across national boundaries. Medical education has the potential to "bridge the digital divide", to enhance health care of underserved populations and education of remote physicians and other healthcare providers ${ }^{2,4,9}$.

Challenges: UNZA-SOM does not have the required access for the web conferencing. Learners' and instructors' training in the ICT is lacking. Learners and instructors are lacking skills in ICT and elearning; they need new skills; e.g., on information search, management and critical appraisal skills and instructors need to be able to teach these skills. Initiatives need to be culturally sensitive, relevant to local health care priorities and supportive of local resources. Incorporating ICT into educational interventions is a challenge for lecturers due to inadequate attention to educational principles and evidence for effective learning. Educational 
outcomes need to be strengthened by instructor and learner preparation for ICT teaching environments, consideration of learners' prior experience and knowledge base, matching learning goals with the specific technology and administrative support. E-learning introduces new demands that impel reviewers to consider aspects that are unique to educational technology, including pedagogy, format, usability, navigation, interactivity, delivery, ease of updating, distribution, and access.

\section{- LinkNet Macha Works}

Macha Mission Hospital in Southern Province is host to an ICT based project that provides 24 hour access to medical and other research information. LinkNet Macha Works ${ }^{14,}{ }^{19}$ has signed a memorandum of understanding with the UNZA School of Engineering to allow the latter's students to engage in rural research attachments, while able to be in touch by ICT with their Lusaka based supervisors. LinkNet is also collaborating with MOH Smartcare initiatives, "Wireless Africa", "Free internet for Africa", and Satellite connectivity Africa Works initiatives with Global Research Alliance.

Opportunities: Quality medical research has been promoted by ICT facilities at Macha, which would have been difficult in this rural area without ICT possibilities. It widens the scope of learning and practicing in a rural setting. Students from School of Engineering, have benefited from the ICT facility, as they have access to ICT/Internet facilities even when away from campus in Lusaka, which feels good for the students as not being that isolated and cut off from their well-known environment. Students and faculty could continue to communicate with peers and supervisors on personal and professional matters, which provided more satisfaction and confidence. The availability of ICT facilities also supported introduction of computer-based resources such as Telemedicine, online training and Internet-based databases at Macha, a rural health site.

Challenges The experience has shown that there is potential of practical placements in rural settings. LinkNet is engaged into development of rural areas and sees potential for UNZA-SOM students and faculty to benefit from the developments taking place in the rural areas, it is a challenge to motivate students and graduate health professionals to gain learning and work experiences in rural areas. In many rural settings, ICT and Internet connectivity are not (yet) as advanced as in Macha, which could be a real role model for rural Zambia. Collaboration between different stakeholders is necessary to achieve optimal benefit for Zambia and provide rural areas with motivated health professionals who are willing to be engaged for a long time in the rural areas. ICT and Internet options could be assets in getting them in the rural areas.

\section{DISCUSSION}

Traditional Medical Education include teacher centred and human resource intense strategies. Without abandoning these traditional teaching methods, evidence has shown that there is a lot of development in innovative medical education strategies. These innovative strategies are aiming to be more student centred, with more pro-activity of the students and aiming for differentiated, deeper, and more competence based learning experiences. The application of ICT is providing opportunities for 
applications of innovations mentioned in Medical Education. ICT and e-learning can support educational goals, advance healthcare education and make it more engaging and interesting for the student as well ${ }^{15,16,17}$. Students could access a diverse range of learning materials on campus and at a distance in the field, away from campus. The learning materials and faculty from well-resources centres in the developed world can be available to lesser resourced such as Zambia. The e-learning initiatives described suggest that there is good potential for e-learning in Zambia, as it was well received and demonstrated many opportunities of elearning for both students and lecturers. It showed that e-learning could be used to the benefit of maximizing learning, aim at better outcomes of the education as it provides the students with different and increased learning experiences. It enhances internal motivation for learning, problem solving and more exposure with less human human resources involved. In an era in which limited human resources weigh heavily on the output and negatively influences delivery of teaching, this could be another welcome advantage of e-learning. However, there are many challenges for UNZASOM before e-learning opportunities can be optimally utilized. Computing equipment and infrastructure for Internet connectivity at UNZA SOM, Ridgeway Campus is still rudimentary and under funded. In Zambia as a whole, bandwidth problems are challenges due to the high price which makes Internet Connectivity expensive and not yet adequate and efficient. Broadband Internet access should become much more widely available in Zambia. Another obstacle at present is that many lecturers and students are still not trained adequately to make maximum use of ICT and e-learning activities. Capacity building in ICT is urgently necessary. Notwithstanding, the underdeveloped elearning expertise, the financial and human resource limitations, e-learning can be promoted through collaboration with partners in the developed world and the private sector and delivered to our students' doorsteps. Nevertheless, UNZA SOM must develop and invest in ICT equipment and infrastructure to make this possible; otherwise the present state of equipment and internet connectivity will preclude our students and faculty from e-learning.

\section{CONCLUSIONS}

The experiences at UNZA SOM with ICT and elearning have been rich and helpful in understanding the potential of it for medical education. At present, due to financial and (human) resources constraints (understaffing), delivery of teaching is not optimal. The experiences showed that e-learning activities can be undertaken with less human resources and provide a variety of excellent learning experiences for students. The positive experiences and responses are promising and stimulate to develop educational activities for students, based on ICT and e-learning, for it to become part of mainstream teaching.

There are many ways in which e-learning can be applied, on an individual basis or collaborative, to be used as a resource or with an interactive element. Although e-learning has become part of mainstream teaching in most medical schools globally, it requires new skills of lecturers 5,15, 16,17, 18, 20, and expertise is still to be developed. This calls for training, technical guidance and innovative challenges for many faculty in order to benefit from this great potential resource. A key area that needs to be addressed relates to the e-learning content, which needs sourcing and contextualizing. Partnering with learning institutions abroad, as UNZA SOM is doing presently, is a most effective way of not only ensuring that appropriate materials are available, but also that the two parties, in Zambia and abroad, can mutually benefit from the interactivity possible. Technology standards are an essential keystone of such collaboration, which include technical, legal, quality assurance, professional and ethical aspects. Synergy between the goals of the education program and those of the local health care community facilitates learning. With e-learning, it is possible to reach beyond the boundaries of the educational institution as it also aims at achieving an exchange within a broader community, enriching courses by exchanging information and expanding knowledge between institutions. Online collaboration can help maximize learning opportunities, especially in Zambia, where teaching staff and resources are limited. Partnering with learning institutions abroad is an effective way to ensure content sourcing, which then needs to be contextualized in providing a more resource-rich environment ${ }^{3,10}$. There is a lot more to be learned than just the shared academic material, and genuinely shared learning experiences are now possible.

Whilst there may be many problems along the road an exciting new journey has now begun. 


\section{ACKNOWLEDGMENTS}

1. Dundee University in the United Kingdo

2. Africonnect in Lusaka, Zambia

3. Royal College of Surgeons in Ireland

\section{REFERENCES}

1. Ellaway R. \& Masters K. (2008) AMEE Guide 32: e Learning in medical education part 1: learning, teaching and assessment. Medical teacher; 30: 455-473.

2. Gormley G., Bickle I., Thomson C. and Kate Collins (2009) Online learning in

clinical skills: the Belfast experience. The Clinical Teacher; 6: 46-55

3. Smothers V, Ellaway R and Greene P. (2008) The E-Learning evolution-leveraging new technology approaches to advance healthcare education. Medical teacher 30: 117-118.

4. Thakore H, McMahon T. (2006) Virtually there: e-learning in medical education. Clinical Teacher; 3(4): 225-228.

5. Morris C. \& McKimm J. (2009) Becoming a digital tourist: a guide for clinical teachers. The Clinical Teacher 6: 51-55.

6. http://www. Youtube.com [accessed 03/04/09]

7. http://www.jisc.ac.uk [accessed 28/03/09]

8. http://www. Unza.zm [accessed 02/04/09]

9. Chang BL, Bakken S, Brown S, Houston TK, Kreps GL, Kukafka R, et al . (2004) Bridging the digital divide: reaching vulnerable populations. J Am Inform Assoc. 11:448-57.

10. Salmoni A. \& Gonzalez M. (2008). Online Collaborative learning: Quantifying how people learn together online. Medical Teacher: 30 (7) $710-716$.
11. Smothers V, Greene P, Ellaway R and Detmer D. (2008) Sharing innovation: the case for technology standards in health professionals education. Medical teacher 30: 150-154

12. http://www.MedEdWorld.com [accessed 10/01/09]

13. Labib M. (2008). A global "School for Surgeons" could help bridge the Healthcare Human Resource Crisis in Sub-Saharan Africa. COSECSA, South Africa.

14. http://www.link.net.zm [accessed 10/03/09]

15. Boerema C., Stanley M. \& Westhorp P. (2007) Educator's perspective of online course design and delivery. Medical Teacher: 29(8) 758-765

16. Hege I., Ropp V., Dler m., Radon K., Masch G., Lyon H. \& Fischer M. (2008) Experiences with different integration strategies of case based elearning. Medical Teacher Medical teacher; 30: 785-790.

17. Hols W., Bloemendaal P., Bos N., Quaak M., Sijstermans R. \& Jong de P. (2008) Twelve tips for computer based assessment in medical education. Medical Teacher; 30:7: 673-678.

18. Johnson SD, Aragon SR. (2003) An instructional strategy framework for online learning environments. New Directions for Adult and Cont. Education Winter. 100:31-40.

19. Stam v G. (2008) "A vision for rural ICT connectivity in Zambia", LinkNet, Presentation Communications Authority Zambia (CAZ) Board meeting December.

20. Yoon SW. (2003) In Search of Meaningful Online Learning Experiences. New Directions for Adult and Cont. Education Winter:100:930 . 